\title{
Alienor method applied to induction machine parameters identification
}

\author{
Latifa Khemici, M'hamed Bounekhla, Elghalia Boudissa
}

Laboratoire De Système Electrique Et Télécommande, Université Saad Dahleb Blida, Algeria

\begin{tabular}{l}
\hline \hline Article Info \\
\hline Article history: \\
Received Dec 1, 2018 \\
Revised Aug 25, 2019 \\
Accepted Aug 30, 2019 \\
\hline
\end{tabular}

\section{Keywords:}

Alienor method

Identification

Induction machine

Parameters estimation

\begin{abstract}
This paper presents an identification method to estimate simultaneously the electrical and mechanical induction machine (IM) parameters by using only the measured current and the corresponding phase voltage. This identification method is based on the output error and uses the multidimensional Alienor global optimization method as a minimization technique. Alienor method is essentially based on converting multivariable problem to monovariable one. To improve the Alienor method performance, the reducing transformation is proposed and compared with the genetic algorithm (GA). Firstly, the identification method is verified using the simulated data. Secondly, the validation is then confirmed by measured data from one machine. The corresponding computed transient and steady state currents agree well with the measured data. The results obtained show the superiority of the proposed Alienor method versus GA in terms of computing time.
\end{abstract}

Copyright $(2020$ Institute of Advanced Engineering and Science. All rights reserved.

\section{Corresponding Author:}

Latifa Khemici,

Laboratoire De Système Electrique Et Télécommande,

Université Saad Dahleb Blida,

B. P. 270, Route de Soumaa, 09000 Blida, Algeria.

Email:1_khemici@yahoo.fr

\section{INTRODUCTION}

Three-phase induction motors are often used in a lot of industrial applications. Because they have many advantages, such as their simple construction, their low price, rigidity and reduced maintenance. They present an effective industrial solution in the field of high-performance drives. However, Efficient control or the analysis of induction motor operation require the instantaneous knowledge of machine parameters [1]. So, these parameters can be obtained by different methods. They can be determined by the classical method, which is based on no-load and locked-rotor tests [2]. But by this method it is not evident to determine easily these parameters, because in the locked-rotor test it is very difficult to lock the rotor, especially for a large size motors. In addition to this, it can have a lack of precision result because of the rotor frequency [3].

In this case, the problem of estimating machine parameters became an optimization problem where we have to minimize the error between an experimental value and a calculated value. Several optimization techniques are presented in the literature [4] to resolve induction machine (IM) estimation. Some of them like the deterministic method require the first or the second derivative [5]. What returns difficult to solve the optimization problem. Among the deterministic method without gradient, we find the Cyclic, Hooke and Jeeves, and the Rosenbrock methods. These techniques are used in [6] to minimize the objective function in order to determine simultaneously the electrical and the mechanical parameters of the IM.

Consequently, evolutionary optimization methods are the ones most used for IM parameters estimation. An adaptive GA is suggested to determine the IM electric parameters in [7, 8]. Four evolutionary techniques (scatter search, evolutionary programming, ant colony, and particle swarm algorithms) were used 
in [9] for off-line identification of IM parameters. An optimization method to estimate the six equivalent circuit parameters by using the particle swarm optimization (PSO) and the genetic algorithm (GA) independently is presented in [10]. For instance, in [11] two particle swarm optimization (PSO) structure approaches are used to estimate simultaneously electrical and mechanical parameters. In [2] a stochastic optimization technique is presented to estimate the equivalent circuit parameters of an induction machine from manufacturer data using the bacterial foraging technique. An improved PSO is presented in [12] to estimate the equivalent circuit parameters of an induction machine. This method integrates the particle swarm with the chaotic sequences to converge directly to the global minima. PSO, differential evolution (DE), and some of their recent variants for in situ efficiency determination of induction motor without performing noload test are presented in [13]. An improved PSO called Systematic Mutation based Particle Swarm Optimization [14] is applied to parameter estimation and efficiency determination, so that parameter variation effect is taken into account. A dynamic real-coded genetic algorithm is applied in [15] to estimate the both of electrical and mechanical parameters.

In [16] a new method is proposed for the parameters estimation of the squirrel-cage induction motors (in the single-cage and double-cage models) based on artificial neural network (ANN) and adaptive neurofuzzy inference system (ANFIS). The method proposed in [17], is based on the differential evolution algorithm. It estimates the parameters of the equivalent electrical circuit, such as stator and rotor resistances and leakage induc-tances, the magnetizing inductance, and also mechanical parameters, such as moment of inertia and the friction coefficient. The performance of this technique is evaluated for three different input signals: current signal of a phase associated with the speed measured from atachogenerator, current signal of a phase associated with the speed acquired from a torquemeter, and only the current signal of one phase. To estimate the equivalent circuit parameters, is presented in [18] an optimization approach based on swarm, wich is called the Artificial Bee Colony (A BC) optimization.by this approach. Two different equivalent circuits are implemented for the parameter estimation scheme; one with parallel and the other with series magnetization circuit.

In spite of their effectiveness to solve complex non-linear optimization problems, the evolutionary methods are characterized by premature convergence and they are greedy in computing time. Therefore, a recent global optimization technique, called Alienor method has been proposed and introduced in any studies [19-21]. It was successfully used to solve different kinds of engineering problems [22-25]. This method is based on transforming the multidimensional problem to one-dimensional problem. In this case the global minimum search becomes simpler.

This paper proposes an optimization approach based on Alienor method, to estimate induction machine parameters. The optimization process starts with transforming the multidimentionel problème to one-dimentional one. So, the electrical and mechanical parameters are given function of one variable. Using only the starting stator current and the corresponding phase voltage, both electrical and mechanical parameters are determined. This is accomplished by minimization of the quadratic output error between the measured current and the computed one. In order to investigate the feasibility of the proposed estimation method, tests on two benchmark functions and on the machine simulated data have been acheived. This algorithm has been tested experimentally by using measured data from a $1.5 \mathrm{KW}$ induction machine. To verify the effectiveness of the proposed method, the obtained results arec ompared with the GA technique results and the measured ones.

The paper is organized as follows. Section 2 presents the research method. In this section it finds, the induction machine model, the identification method and a clarification of the Alienor method. The method is used to determine simultaneously the electrical and mechanical parameters of an induction machine from the measured current and the corresponding phase voltage. Results and discussion are sumerized in Section 3, where, the simulation and the experimental results are given to show the validity of the developed method. The paper is completed by a conclusion in Section 4.

\section{RESEARCH METHOD}

\subsection{Induction machine model}

For this study, it has used the IM mathematical model (parks' model) presented as follow by using the usual hypothesis (the saturation effect and skin effect are neglected, only one space harmonic is considered, the air gap constant). The present induction machine equations are related to a reference linked to the stator [1].

$$
\frac{d i}{d t}=A I+B U
$$


Where:

$$
\begin{aligned}
I & =\left[\begin{array}{llll}
I_{d s} & I_{q s} & I^{\prime}{ }_{d r} & I^{\prime}{ }_{q r}
\end{array}\right]^{t} \\
U & =\left[\begin{array}{lllll}
V_{d s} & V_{q s}
\end{array}\right]^{t} \\
A & =\left[\begin{array}{cccc}
-\frac{1}{\sigma T_{s}} & \frac{1-\sigma}{\sigma} p_{0} \omega & \frac{1-\sigma}{\sigma T_{r}} & \frac{1-\sigma}{\sigma} p_{0} \omega \\
-\frac{1-\sigma}{\sigma} p_{0} \omega & -\frac{1}{\sigma T_{s}} & -\frac{1-\sigma}{\sigma} p_{0} \omega & \frac{1-\sigma}{\sigma T_{r}} \\
\frac{1}{\sigma T_{s}} & -\frac{1}{\sigma} p_{0} \omega & -\frac{1}{\sigma T_{r}} & -\frac{1}{\sigma} p_{0} \omega \\
\frac{1}{\sigma} p_{0} \omega & \frac{1}{\sigma T_{s}} & \frac{1}{\sigma} p_{0} \omega & -\frac{1}{\sigma T_{r}}
\end{array}\right] \\
B & =\left[\begin{array}{cc}
\frac{1}{\sigma L_{s}} & 0 \\
0 & \frac{1}{\sigma L_{s}} \\
-\frac{1}{\sigma L_{s}} & 0 \\
0 & -\frac{1}{\sigma L_{s}}
\end{array}\right]
\end{aligned}
$$

The mechanical equation is given as follow:

$$
\begin{aligned}
& J \frac{d \omega}{d t}=C_{e m}-C_{l}-C_{r e s} \\
& C_{e m}=p_{0} \frac{L_{m}^{2}}{L_{r}}\left(I_{q s} I_{d r}^{\prime}-I_{d s} I_{q r}^{\prime}\right) \\
& C_{r e s}=f r . \omega
\end{aligned}
$$

The dynamic model with four electrical parameters and two mechanical parameters is formulated by the following set (9):

$$
\left\{\begin{array}{l}
\frac{d}{d t} I_{d s}=-\frac{1}{\sigma T_{s}} I_{d s}+\frac{1-\sigma}{\sigma} p_{0} \omega I_{q s}+\frac{1-\sigma}{\sigma T_{r}} I_{d r}^{\prime}+\frac{1-\sigma}{\sigma} p_{0} \omega I_{q r}^{\prime}+\frac{1}{\sigma L_{s}} V_{d s} \\
\frac{d}{d t} I_{q s}=-\frac{1-\sigma}{\sigma} p_{0} \omega I_{d s}-\frac{1}{\sigma T_{s}} I_{q s}-\frac{1-\sigma}{\sigma} p_{0} \omega I^{\prime}{ }_{d r}+\frac{1-\sigma}{\sigma T_{r}} I_{q r}^{\prime}+\frac{1}{\sigma L_{s}} V_{q s} \\
\frac{d}{d t} I_{d r}^{\prime}=\frac{1}{\sigma T_{s}} I_{d s}+-\frac{1}{\sigma} p_{0} \omega I_{q s}+-\frac{1}{\sigma T_{r}} I_{d r}^{\prime}+-\frac{1}{\sigma} p_{0} \omega I_{q r}^{\prime}+-\frac{1}{\sigma L_{s}} V_{d s} \\
\frac{d}{d t} I_{q r}^{\prime}=\frac{1}{\sigma} p_{0} \omega I_{d s}+\frac{1}{\sigma T_{s}} I_{q s}+\frac{1}{\sigma} p_{0} \omega I_{d r}^{\prime}-\frac{1}{\sigma T_{r}} I^{\prime}{ }_{q r}-\frac{1}{\sigma L_{s}} V_{q s} \\
\frac{d}{d t} \omega=\frac{p_{0}}{J} L_{s}(1-\sigma)\left(I_{q s} I_{d r}^{\prime}-I_{d s} I^{\prime}{ }_{q r}\right)-\frac{f r . \omega}{J}
\end{array}\right.
$$

Consequently, the parameters vector is given by:

$$
p_{v}=\left[\begin{array}{lllll}
\sigma, & T_{r}, \quad L_{s}, \quad T_{s}, \quad J, & f r
\end{array}\right]
$$

Thus, the IM is characterized by the parameters vector $p_{v}$. This vector is obtained from the measurement of the current and the corresponding voltage applied to the machine. 


\subsection{Identification method}

To estimate the parameters vector $p_{v}$, the objective function $E$ is minimized by the Alienor method. The proposed algorithm minimize the quadratic error between the experimental current $I_{m e s}$ and the calculate one $I_{c a l}$. The objective function is given by:

$$
E=\sum_{i=1}^{n}\left(I_{m e s i}-I_{c a l i}\right)^{2}
$$

Where $n$ is the number of the experimental values.

The used identification method is presented in Figure 1. To estimate the vector of parameters $p_{v}$, the objective function $\mathrm{E}$ is minimized by using the Alienor method.

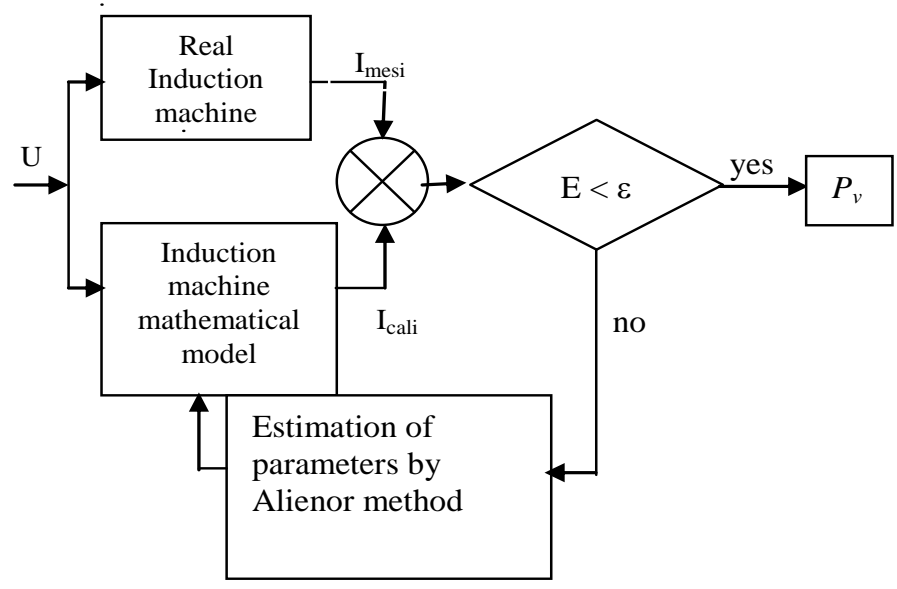

Figure 1. Block diagram of the identification method

\subsection{The Alienor method}

The Alienor method is based on transforming a multi-dimensional optimization problem to a one dimensional optimization problem using a reducing transformation [21]. The based reducing transformation use the properties of the Archimedes' spiral [22], where variables are determined by their polar coordinates. For example: when it has two variables $x_{1}$ and $x_{2}$. In first, these ones are determined as:

$$
x_{1}=r \cos \theta \text { and } x_{2}=r \sin \theta
$$

The relation between $r$ and $\theta$ can be fined by the Archimedes' spiral, where the equation is $r=a \theta, \theta \geq 0$. and $a \geq 0$ (Fixed and destined to tender to zero). Then, the two variables are obtained as follow:

$$
x_{1}=a \theta \cos \theta=h_{1}(\theta) \quad x_{2}=a \theta \sin \theta=h_{2}(\theta)
$$

Finally, the two variables $x_{1}$ and $x_{2}$ are expressed as a function of the unique variable $\theta$. This reducing transformation can be used for $\boldsymbol{n}$ variables $(\boldsymbol{n}>2)$. But when the number of variables increase, it will be difficult to determine the functions $h i(\theta)$. Because they are not obtained in only one step [26], where the computing time is proportional to the number of variables. After, it has proposed many reducing transformations [27] which enable us to determine the functions $h i(\theta)$ in only once, which brings back for us to facilitate calculations when we have a large number of variables. The Alienor's method can be used for solving an optimization problem which is summarized as follow:

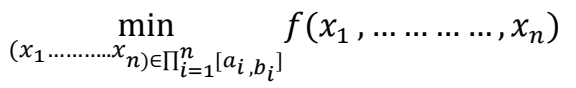

Where $f$ is a continuous function.

The variables $x_{i}$ are substituted by the reducing transformation 


$$
x_{i}=h_{i}(\theta), \quad i=1 \ldots \ldots \ldots \ldots \ldots, n
$$

So, we obtain the following approached problem

$$
\min _{\theta \in\left[0, \theta_{\text {max }}\right]} g(\theta)
$$

Where $g(\theta)=f\left(h_{1}(\theta), \ldots \ldots \ldots \ldots, h_{1}(\theta)\right)$, which is a function with a single variable. $\theta_{\max }$ is the maximum value of $\theta$. To solve this one-dimensional minimization problem, we can follow steps given in $[21,26]$. So the interval $\left[0, \theta_{\max }\right]$ is discredited into $N$ points, with a chosen step $\Delta \theta$, where $\theta_{\max }=N \Delta \theta$. Then we look for the absolute minimum in the set $g\left(\theta_{j}\right)$, where $j=1,2, \ldots \ldots \ldots, N$. . Once the global solution of this optimization problem is obtained for an $\theta^{*}$, the reducing transformation given in (14) is used to deduce the variables $x_{i}$ as follows:

$$
x_{i}=h_{i}\left(\theta^{*}\right)
$$

\subsubsection{The used reducing transformation}

In this part we present the reducing transformation which is used to transform the minimized function to a function of only a single variable. We have use the konfé-cherruault [22] transformation, which is defined by:

$$
x_{i}=h_{i(\theta)}=(1 / 2)\left[\left(b_{i}-a_{i}\right) * \cos \left(w_{i} \theta+\varphi_{i}\right)+\left(b_{i}+a_{i}\right)\right]
$$

The Choice of the parameters is given as flows:

$w_{i}$ and $\varphi_{i}$ are two slowly growing sequences.

$a i$ and $b i$ are the bounded value of the variable $x_{i}\left(x_{i} \in\left[a_{i}, b_{i}\right]\right)$.

$\theta \in\left[0, \theta_{\max }\right]$. Where $\theta_{\max }$ is the maximum value of $\theta$. So, each reduction transformation has a method for calculate the $\theta_{\max }$. For this one we can calculate the $\theta_{\max }$ as flow $[26,28]$ :

$$
\theta_{\max }=\max \left(\frac{\left(b_{i}-a_{i}\right) \theta_{1 \max }+\left(b_{i}+a_{i}\right)}{2}\right)
$$

Where:

$$
\theta_{1 \max }=\frac{2 \pi-\varphi_{1}}{\omega_{1}}
$$

\section{RESULTS AND DISCUSSION}

\subsection{Simulation results}

A numerical program based on Alienor method is applied to simultaneously a benchmark functions and a simulated data of an induction machine.

\subsubsection{Benchmark functions}

To prove the validity of the Konfé-Cherrualt transformation, we are brought back to apply it on two benchmark functions. Table 1 shows the minimization problems which are chosen. The reducing transformation defined by the (17) is used to define the variables $x_{i}$. With $\theta \in\left[0, \theta_{\max }\right]$, which is calculated according to (18). In Table 2 the values of $\theta_{\max }$ and $\theta^{*}$ are illustrated. $\theta_{\max }$ is calculated by (18), (16) and $\theta^{*}$ is the obtained solution of the problem defined by (15). The optimal solutions $x_{i}$ are deduced using the reducing transformation (17) where $\theta=\theta^{*}$. Table 3 shows the given and the simulated solutions. According to the simulation results presented in Table 3 , it can be noticed that the obtained results are very satisfactory. So, the Alienor method and the developed program are valid. 
Table 1. Benchmark functions

\begin{tabular}{|c|c|c|}
\hline Function & Test area & Reducing transformation \\
\hline $\begin{array}{c}\text { Rosenbrock } \\
f\left(x_{1}, x_{2}\right)=100\left(x_{2}-x_{1}^{2}\right)^{2}+\left(1-x_{1}\right)^{2}\end{array}$ & {$[-5,5] \times[-5,5]$} & $\begin{array}{c}x_{1}=h_{1(\theta)}=(1 / 2)[(5+5) * \cos (1500 \theta+0,05) \\
+(-5+5)] \\
x_{2}=h_{-}(2(\theta))=(1 / 2)[(5+5) * \cos (1500,0001 \theta \\
+0,0505)+(-5+5)]\end{array}$ \\
\hline $\begin{array}{c}\text { Six-hump camel back } \\
f\left(x_{1}, x_{2}\right)=\left(4-2.1 x_{1}^{2}+\frac{x_{1}^{4}}{3}\right) x_{1}^{2}+x_{1} x_{2} \\
+\left(-4+4 x_{2}^{2}\right)\end{array}$ & {$[-3,3] \times[-2,2]$} & $\begin{array}{c}x_{1}=h_{1(\theta)}=(1 / 2)[(3+3) * \cos (2132 \theta)+(-3 \\
+3)] \\
x_{2}=h_{2(\theta)}=(1 / 2)[(2+2) * \cos (2133 \theta+0,0005) \\
+(-2+2)]\end{array}$ \\
\hline
\end{tabular}

Table 2. Parameters $\theta_{\max }$ and $\theta^{*}$

\begin{tabular}{ll}
\hline Rosenbrock & Six-hump camel back \\
\hline$\theta_{\max }=5.0208$ & $\theta_{\max }=3.0088$ \\
$\theta^{*}=1.0397$ & $\theta^{*}=0.3942$ \\
\hline
\end{tabular}

Table 3. Given and estimated solution

\begin{tabular}{ccc}
\hline Benchmark function & Given solution & Simulated solution \\
\hline Rosenbrock & $x_{1}=1$ & $x_{1}=0,9970$ \\
& $x_{2}=1$ & $x_{2}=0,9941$ \\
& $\min \left(f\left(x_{1}, x_{2}\right)\right)=0$ & $\min \left(f\left(x_{1}, x_{2}\right)\right)=8,798 \times 10^{-6}$ \\
Six-hump & $x_{1}=-0.0898$ or 0.0898 & \\
& $x_{2}=0.7126$ or -0.7126 & $x_{1}=-0,0922$ \\
& $\min \left(f\left(x_{1}, x_{2}\right)\right)=-1.0316$ & $x_{2}=0,7119$ \\
& & $\min \left(f\left(x_{1}, x_{2}\right)\right)=-1.0316$ \\
\hline
\end{tabular}

\subsubsection{Simulated data}

To make sure of the developed method efficiency, the Alienor estimated parameters are compared with given parameters of an IM feed by a sine voltage and they are also compared with the GA estimated parameters. Using the Runge-Kutta method, simulated data are obtained by the numerical solution of (9) with given motor parameters. Figure 2 shows the sample sinusoidal voltage and the corresponding current

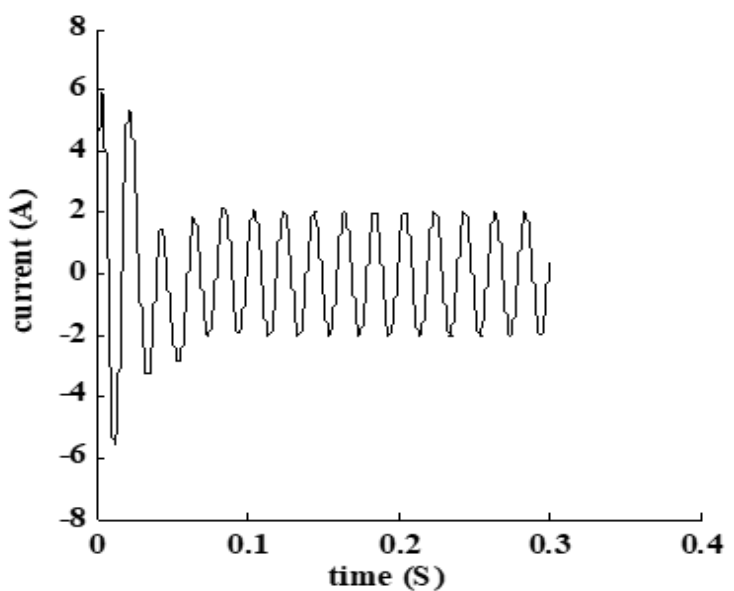

(a)

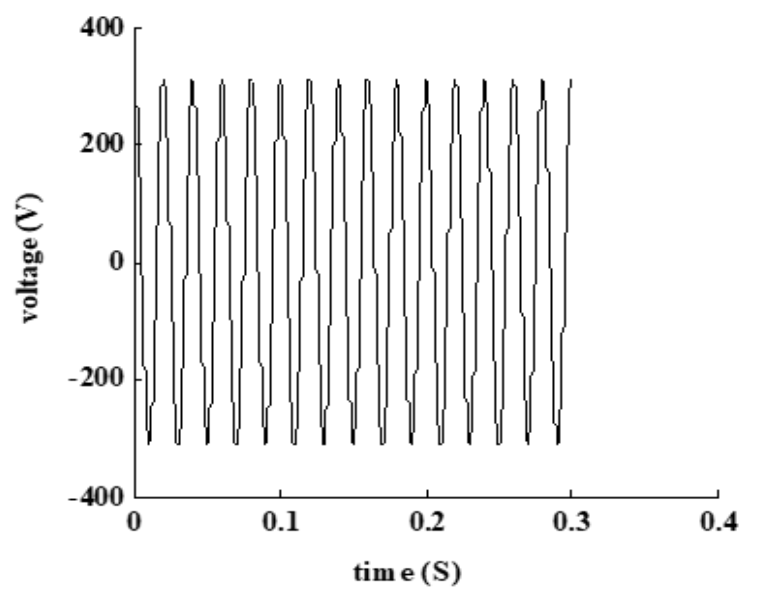

(b)

Figure 2. (a)Voltage supply and (b) the corresponding starting stator current 
By using the reducing transformation (17), the parameters vector is given as follows:

$$
\begin{aligned}
& \sigma=h_{1(\theta)} \\
& T_{r}=h_{2}(\theta) \\
& L_{s}=h_{3(\theta)} \\
& T_{s}=h_{4(\theta)} \\
& J=h_{5(\theta)} \\
& f_{r}=h_{6(\theta)}
\end{aligned}
$$

With:

$\theta \in\left[0, \theta_{\max }\right]$. Where $\theta_{\max }=0.34668$, which is calculated by (17) and (18).

And:

$$
\begin{aligned}
& \omega_{1}=150, \omega_{2}=1500, d \omega=1, \text { And } \omega_{i}=\omega_{i-1}+d \omega \text { with } i=3 \text { to } 6 \\
& \varphi_{1}=0, \varphi_{2}=0, \varphi_{i}=\varphi_{i-1}+d \varphi \text { with } i=3 \text { to } 6
\end{aligned}
$$

The bounded values $a i$ and $b i$ are respectively fixed as follow:

$[0.0100,0.4320] \times[0.0001,0.0326] \times[0.0500,0.7155] \times[0.0001,0.0840] \times[0.0001,0.0093] \times[0.0001,0.0410]$. It has used a step $\Delta \theta=10^{-3}$

With the develop program, it find the optimal solution of the problem defined by $(15), \theta^{*}=0.072$. Then using (17), the estimated parameters are deduced. Table 4 shows the obtained results as well as the given parameters and the GA estimated ones. One can see the agreement between the estimated parameters and the given ones. In addition, it found that the Alienor method presents a better number of iterations and a reduced time computing compared with GA method.

Table 4. Parameters identification result

\begin{tabular}{cccc}
\hline Parameters & Given parameters & Estimated parameters Alienor & Estimated parameters GA \\
\hline$\sigma$ & 0.1800 & 0.17999 & 0.18000 \\
$T_{r}(s)$ & 0.0225 & 0.02245 & 0.02250 \\
$L_{s}(H)$ & 0.4850 & 0.48503 & 0.48499 \\
$T_{s}(s)$ & 0.0520 & 0.05201 & 0.05200 \\
$J\left(k g . m^{2}\right)$ & 0.00548 & 0.00546 & 0.00547 \\
$f_{r}(N m . s / R d)$ & 0.02250 & 0.02248 & 0.02250 \\
Number of iterations & & 347 & 367 \\
Time computing (S) & & 155.381 & 296,02 \\
\hline
\end{tabular}

\subsection{Experimental results}

The program based on Alienor method is applied to estimate the induction machine parameters. The experimental tests are implemented on a 3-phase induction machine with the following characteristics: 4 poles, $220 \mathrm{~V} / 380 \mathrm{~V}$, and $1.5 \mathrm{KW}$. The startup current and the corresponding phase voltage are simultaneously measured. Figure 3 represents respectively the measured current and the corresponding voltage.

With $\theta_{\max }=0.50251$

$$
\begin{aligned}
& \omega_{1}=150, \omega_{2}=1500+d \omega, d \omega=0.068 \\
& \text { And } \omega_{i}=\omega_{i-1}+d \omega \text { with } i=3 \text { to } 6 \\
& \varphi_{1}=0.06,=0.006, \varphi_{i}=\varphi_{i-1}+d \varphi \text { with } i=2 \text { to } 6
\end{aligned}
$$

And the bounded values $a i$ and $b i$ are respectively fixed as follow: $[0.00001,0.08740] \times[0.05000,0.84600] \times[0.09000,1.05500] \times[0.00400,0.83600] \times[0.00100,0.35500] \times[0.00700$, $0.03800]$. For this problem it has chosen a step $\Delta \theta=10^{-3}$.

With the develop program, it find the optimal solution of the problem defined by (15), $\theta^{*}=0.077$. Table 5 shows results obtained using the measured data for the chosen $\Delta \theta$. Comparative study with the GA method was made to justify the performance results of the proposed algorithm. From these results, it can be clearly seen that the parameters obtained by the two optimization methods are close to one another. On the other hand, in view of the number of iterations and time computing it notices that the Alienor method gives a better result compared to the GA method. The estimated parameters for the Alienor and the GA methods are used for obtaining the calculated currents. Figure 4 shows 
the superposition of the calculated currents over the measured one. One can see that the calculated currents are closer to the measured one.

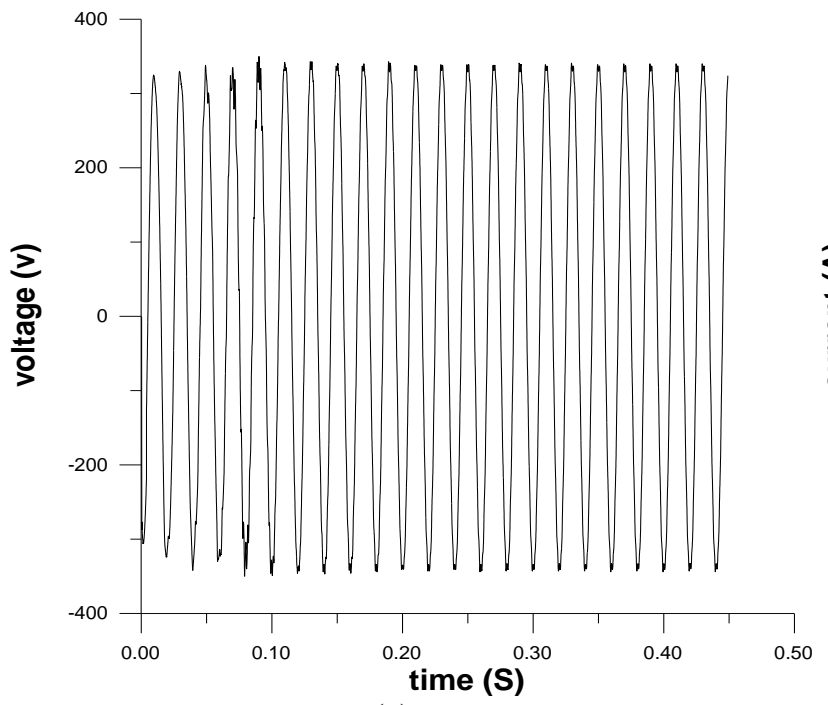

(a)

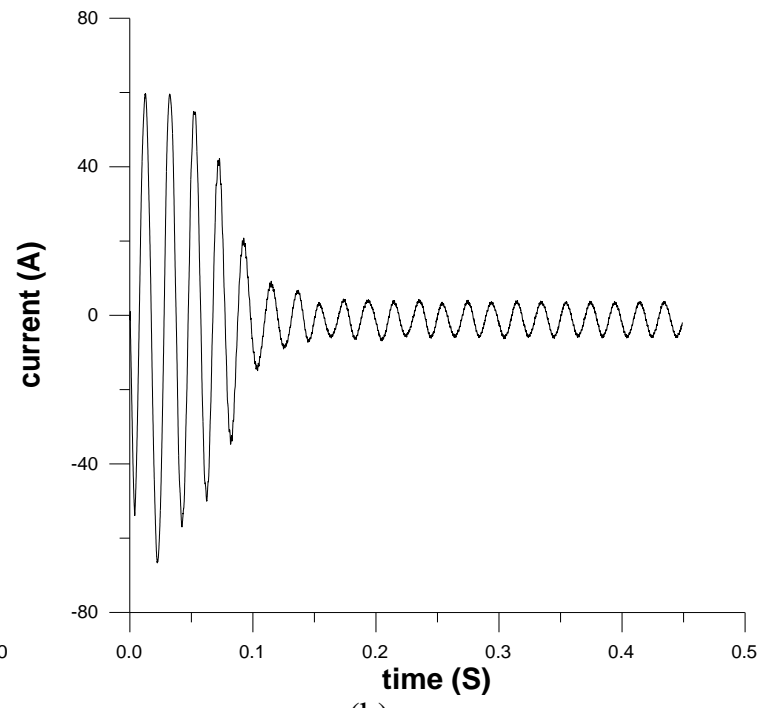

(b)

Figure 3. (a) Voltage measured; (b) current measured

Table 5. Results of estimated parameters

\begin{tabular}{ccc}
\hline Parameters & Estimated parameters Alienor & Estimated parameters GA \\
\hline$\sigma$ & 0.06889 & 0.06890 \\
$T_{s}(s)$ & 0.13546 & 0.13530 \\
$L_{s}(H)$ & 0.19028 & 0.19010 \\
$T_{r}(s)$ & 0.08762 & 0.08750 \\
$J\left(\mathrm{~kg} \cdot \mathrm{m}^{2}\right)$ & 0.03539 & 0.03530 \\
$f_{r}(\mathrm{Nm} . \mathrm{s} / \mathrm{Rd})$ & 0.00990 & 0.09900 \\
Number of iterations & 503 & 1211 \\
Computing Time $(\mathrm{S})$ & 420.438 & 30755.228 \\
\hline
\end{tabular}

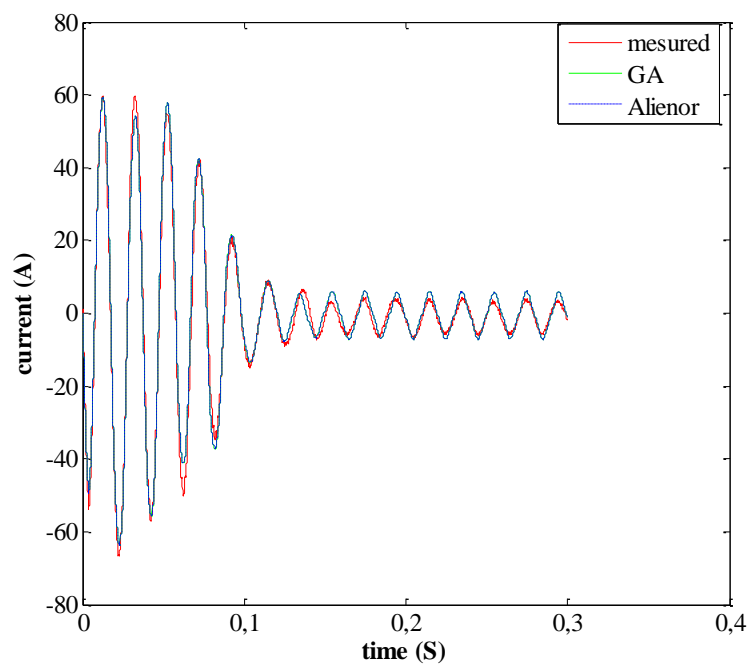

Figure 4. Superposition of the measured current and calculated ones with the estimated parameters 


\section{CONCLUSION}

In this paper, an efficient identification method of IM is presented. The electrical and mechanical parameters of an IM are determined simultaneously by using only the measured current and the corresponding phase voltage. This identification method is based on the output error and uses the Alienor method as a minimization technique. The reducing transformation is proposed in order to improve the Alienor method performance. There is applied on two benchmarked functions. By simulated data from known parameters induction machine, the method is successfully tested, and it is found to retrieve the model parameters with high accuracy. The result shows that the proposed Alienor methods finds the optima more quickly and possess a lower computing time than GA. Using measured data on one machine, the effectiveness of the method is very suitable since it is well confirmed by the good parameters obtained showing the corresponding computed transient and steady state currents agree well with the measured data. The results obtained show the superiority of the proposed Alienor method versus GA in terms of computing time and convergence speed.

\section{REFERENCES}

[1] E.C. Quispe, I.D. López, F.J. T. E. Ferreira, V. Sousa, "Unbalanced Voltages Impacts on the Energy Performance of Induction Motors," International Journal of Electrical and Computer Engineering (IJECE), vol. 8, no. 3, pp. 1412-1422, Jun 2018.

[2] J. Chatelain, Machines électriques. Traité d'électricité, Presses Polytechniques Romandes, Lausanne, vol. 10, 1983

[3] V. P. Sakthivel, R. Bhuvaneswari, S. Subramanian, "Bacterial Foraging Technique Based Parameter Estimation of Induction Motor from Manufacturer Data," Electric Power Components and Systems, vol. 38, no. 6, pp. 657-674, 2010

[4] D.G. Luemberger, Linear and non linear programming, Addison Wesley, 1989.

[5] M.S. Bazaraa, H.D. Sherall, and C.M. Shetty, Non linear programming theory and algorithms, John Wiley \& Sons inc., 1993.

[6] M. Bounekhla, M.E Zaim, A. Rezzoug, "Comparative study of three minimization methods applied to the induction machine parameters Identification using transient stator current," Electric Power Components and Systems, vol. 33, no. 8, pp. 913-930, 2005.

[7] B. Abdelhadi, A. Benoudjit, N. Nait Said, "Identification of Induction Machine Parameters Using a New Adaptive Genetic Algorithm," Electric Power Components and Systems, vol. 32, no. 8, pp. 767-784, 2004.

[8] B. Abdelhadi, A. Benoudjit, and N. Nait-Said, "Application of Genetic Algorithm with a Novel Adaptive Scheme for the Identification of Induction Machine Parameters," IEEE transactions on energy conversion, vol. 20, no. 2, pp. 284-291, 2005.

[9] N. Benaïdja, N. Khenfer, "Identification of Asynchronous Machine Parameters by Evolutionary Techniques," Electric Power Components and Systems, vol. 34, no. 12, pp. 1359-1376, 2006.

[10] MA. Awadallah, "Parameter Estimation of Induction Machines from Nameplate Data Using Particle Swarm Optimization and Genetic Algorithm Techniques," Electric Power Components and Systems, vol. 36, no. 8, pp. 801-814, 2008

[11] M. Bounekhla, et al., "Using two PSO structure approaches to estimate induction machine parameters," 13th European Conference on Power Electronics \& Applications (EPE), Barcelona, Spain, Sep 2009.

[12] V.P. Sakthivel, R. Bhuvaneswari, S. Subramanian, "An Improved Particle Swarm Optimization for Induction Motor Parameter Determination," International Journal of Computer Applications, vol. 1, no. 2, pp. 62-67, 2010.

[13] R. Thangaraj, M. Pant, C. Thanga Raj, AK. Nagar, "In Situ Efficiency Determination of Induction Motor: A comparative study of evolutionary techniques," Applied Artificial Intelligence, vol. 25, no. 2, pp. 116-140, 2011.

[14] J. G. Yadav, S. P. Srivastava, "New Improved PSO Based Parameter Estimation for Energy Efficient Control of Induction Motor Drive," International Journal of Electronics Engineering, vol. 4, no. 1, pp. 95- 99, 2012.

[15] E. Boudissa, M. Bounekhla, "Genetic Algorithm with Dynamic Selection Based on Quadratic Ranking Applied to Induction Machine Parameters Estimation," Electric Power Components and Systems, vol. 40, no. 10, pp. 1089-1104, 2012.

[16] M.A. Jirdehi, A. Rezae, "Parameters Estimation of Squirrel-Cage Induction Motors Using ANN and ANFIS," Alexandria Eng. J., 2016.

[17] J.J. Guedes, M.F. Castoldi, A. Goedtel, C.M. Agulhari, D.S. Sanches, "Parameters estimation of three-phase induction motors usingdifferential evolution," Electric Power Systems Research, vol. 154, pp. 204-212, 2018.

[18] M. Aminu, "A Parameter Estimation Algorithm for Induction Machines Using Artificial Bee Colony (ABC) Optimization," Nigerian Journal of Technology (NIJOTECH), vol. 38, no. 1, pp. 193-201, 2019.

[19] Y. Cherruault, "A New Method for Global Optimization (Alienor)," Kybernetes, vol. 19, no. 3 pp. 19-32, 1990.

[20] G. Mora, Y. Cherruault, "Characterization and Generation of $\alpha$-Dense curves," Computers Math. Applic., vol. 33, no. 9, pp. 83-91, 1997.

[21] A. Ziadi, Y. Cherruault, G. Mora, "Global Optimization: A New Variant of the Alienor Method," Computers Math. Applic., vol. 41, pp. 63-71, 2001. 
[22] Y. Cherruault, "Global Optimization in Biologie and Medicine," Mathl. Computers Modeling, vol. 20, no 6, pp. 119-132, 1994

[23] G. Idiri, S. Djennoune, M. Bettayeb, "Solving FixedFinal Time Fractional Optimal Control Problems Using the Parametric Optimization Method," Asian Journal of Control, vol. 18, no. 5, pp. 1-13, 2016.

[24] A. Thamallah, A. Sakly, F. M'Sahli, "Particle Swarm Optimization and Alienor Method to Constrained Multivariable Predictive Control," 17th international conference on Sciences and Techniques of Automatic control \& computer engineering - STA'2016, Sousse, Tunisia, pp. 61-66, 2016.

[25] N.A. Messaoudi, S. Manseur, M. Blidia, "Optimal Control of Parabolic PDE by a Combined ADOMIAN/ ALIENOR Model," Advanced Studies in Contemporary Mathematics, vol. 27, no. 3, pp. 361-371, 2017.

[26] B.O. Konfé, Y. Cherruault, T. Benneouala, "A global optimization method for a large number of variables (variant of Alienor method)," Kybernetes, vol. 34, pp. 1070-1083, 2005.

[27] D.Lavigne, Y. Cherruault, "Alienor-Gabriel Global Optimization of a function of several variables," Mathl. Computers Modeling, vol. 20, no. 6, pp. 119-132, 1994.

[28] M. Maimos, B.O. Konfe, S. Koussoube, B. Some, "Alienor Method for Nonlinear Multi-Objective Optimization," Applied Mathematics, vol. 2, pp. 217-224, 2011.

\section{BIOGRAPHIES OF AUTHORS}

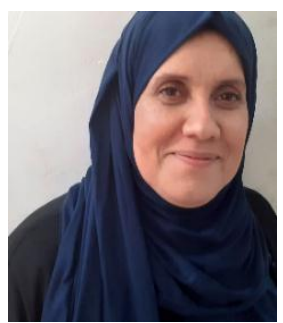

Latifa Khemici is a lecturer at University Saad Dahleb of Blida, Algeria. She is member of ECME team, working on electrical machine control in the SET Laboratory. She received the electronic engineering degree from University of Blida in 1997 and the Master degree in control from University of Blida in 2003. Her main research activities deal with non-linear systems, identification and optimization with application to induction machines.

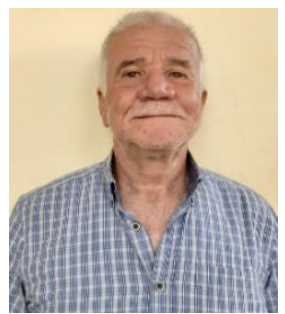

M'hamed Bounekhla is a member of ECME team working on electrical machine control in the SET laboratory at University Saad Dahleb of Blida (USDB), Algeria. He received the electromecanique engineering degree from ENITA Bordj el Bahri, Algeria in 1979, the Master degree in electrical machine from the national polytechnic school of Algiers (ENPA), Algeria in 1991, and the Ph.D. degree in electrical machine from the national polytechnic school of Algiers (ENPA), Algeria in 2004. His main research interests include non linear systems, optimisation and identification with application to induction machines.

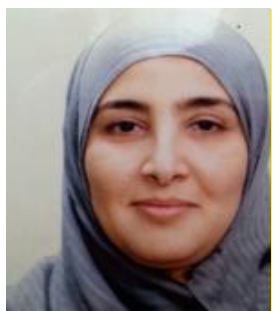

El-ghalia Boudissa is a lecturer at University Saad Dahleb of Blida, Algeria. She is member of ECME team, working on electrical machine control in the SET Laboratory. She received the electronic engineering degree from University of Blida in 1991, and the Master degree in control from University of Tizi ouzou in 2000, and the Ph.D. degree in control from University of Blida, Algeria in 2013. Her main research activities deal with non-linear systems, identification and optimization by genetic algorithms and pso with application to induction machines. 